\title{
WHAT'S AT STAKE IN DIGITAL SOCIAL RESEARCH?
}

\author{
Nick Couldry
}

\begin{abstract}
I am a social researcher who uses both theoretical and empirical enquiry not so much to describe the social as to understand the conflicts involved in constructing an order that appears to us as 'social'. I seek to address the paradox of doing social research: for the social is not something concrete at which we can point, but a dimension of how whatever in our life is concrete holds together as a world. Media are crucial to what hangs together as a world - and in ways that much social research to this day still ignores. Media are in the contemporary era irrevocably 'digital': they take forms that automatically bring possibilities for recombination, retransmission, and reworking by multiple actors. As such, and unavoidably, digital media can be woven tight into the fabric of social life much more than previous media. But what does this mean for the social world, that is, for our possibilities to enhance or undermine how we live together today?
\end{abstract}

"London School of Economics, United Kingdom. 
If asked to categorize my work, I would probably say that I am a social researcher who uses both theoretical and empirical enquiry not so much to describe the social as to understand the conflicts involved in constructing an order that appears to us as 'social'. This might seem rather roundabout, even evasive, but anything briefer would cover over the paradox of doing social research: for the social is not something concrete at which we can point, but a dimension of how whatever in our life is concrete holds together as a world.

Media are crucial to what hangs together as a world - and in ways that much social research to this day still ignores. Media are in the contemporary era irrevocably 'digital': they take forms that automatically bring possibilities for recombination, retransmission, and reworking by multiple actors. As such, and unavoidably, digital media can be woven tight into the fabric of social life much more than previous media. But what does this mean for the social world, that is, for our possibilities to enhance or undermine how we live together today? It is that question that I suggest is at stake in debates about how best to do digital social research.

\section{A PERSONAL ASIDE}

That said, I would now give a different sort of answer to the question of what's at stake in digital social research than I would have given in the early years of this decade. At that time, my priority in thinking about media through a social lens was to avoid two contrasting forms of reductionism. On the one hand, a media-centrism that took off from the undoubted role of digital media (especially social media platforms) in the texture of daily life to proclaim that we lived, already, a 'media life': Mark Deuze's elegant book (2012) was the best-known version of this move. My concern was that it unwittingly closed off from view the still difficult, still highly contestable, ways in which media come to occupy this indispensable role in contemporary life - ethically, politically, and socially. On the other hand, I wanted also to resist a reductionism coming from 'social theory' that collapsed all inherited accounts of the social world in favour of a new language of networks, assemblages, and sheer heterogeneity: I mean the many offshoots of Bruno Latour's work in Actor Network Theory, including various forms of STS ('science and technology studies'). This concern cut across my huge admiration for Latour's achievement in reformulating our understanding of the material basis of what sociologists still call 'power'. Yet what was lost in the process, and particularly in Latour's grander proclamations (for example Latour 2005), was any sense of what remained stable and consistent in the dizzying complexities of how combinations of human and nonhuman actors somehow worked together to produce something like order. In particular, what was lost was any grasp of the enduring importance of the work of representation, including of course media institutions' role in representing the world (Couldry 2004; Couldry 2012, pp. 30-31). 
In response to these twin reductionisms, one from media theory and one from social theory, I offered what I called a 'socially oriented media theory': an approach to thinking about social life and 'media life' that 'addresses the construction, representation and contestation of the social' (Couldry 2012, p. 8), and media's role in that often submerged process. That, in a sense, had been my interest from the start of my research career through what previously I formulated from the perspective of media institutions, and their construction of themselves as central: 'the myth of the mediated centre' (Couldry 2012, chapter 3). For sure that myth worked through a discourse by media about the social, and what hold people and institutions in communication with each other in a particular territory. But in my earlier work the construction of the social itself received less emphasis.

What I did not expect at the start of this decade was how crucial that question of the construction of the social would become as a vantage-point from which to think about what media do. That all changed when I began to register, rather later than some, the work of data within media production and thereby in social production. Two experiences were crucial in this shift in my perspective.

The first was being part of the CultureDigitally network of academics founded by Tarleton Gillespie and Hector Postigo in 2010 which brought together people (from games designers to historians and anthropologists) at various career stages to think together about what was happening to culture in the digital age: its debates still continue in an online form ${ }^{1}$. Being part of this network challenged me to continue expanding the theoretical formulations of the book on which I was then working (Media Society World, from which I have already quoted to encompass a far-wider range of computer-driven forms than I discuss in that book.

The second key experience, in parallel, was my huge privilege in leading what became the Storycircle project at Goldsmiths, University of London. ${ }^{2}$ One moment in that project was crucial. In a project about digital storytelling, but certainly not about data, we found that essential to the experience of running a local organization for giving voice to local people was the management of data around that organization's website: understanding how people moved around it, why they did or often did not - feel disposed to click on links or recirculate videos they had just seen. The world of social action, we started to realise, was suffused not just with media (of course it was!) but with processes of datafication and the measurement of data. We coined a term for a social research perspective that could register this: 'real social analytics' (Couldry, Dickens and Fotopoulou 2016). This is not the place to go into the detail of that idea, but the key point here is that I had caught up, finally, with a transformation that was already troubling - or exciting - many scholars: the role of algorithmic processing of data in constructing the worlds of appearance that pass for reality under particular conditions, pressures and needs.

\footnotetext{
${ }^{1}$ See http://culturedigitally.org/

${ }^{2} \mathrm{https} / / /$ storycircleuk.wordpress.com/ The team of researchers was myself (current institution, LSE), Richard Macdonald (Goldsmiths), Wilma Clark (independent researcher), Luke Dickens (Kings College, London), Aristea Fotopoulou (Brighton), and Hilde Stephansen (Westminster).
} 
From that point on, I realised that my own long-term project of understanding how media construct themselves as central institutions, and in turn construct the social for their audiences, had been, itself, reoriented towards a new focus: computational processes that, to be honest, I had not previously set out to study at all.

I do not delude myself that this 'conversion' to interest in datafication is unique: on the contrary, it seems to characterize many colleagues in the interdisciplinary space of digital social research, and from all parts of the world. Under way is a profound and by no means entirely voluntary shift in the centre of gravity of information and communications over the past decade, which is changing the terms of digital social research.

\section{SOME PRINCIPLES FROM SOCIAL THEORY}

What then do I draw from this personal journey in terms of principles that a socialtheoretic perspective might offer to debates on new directions for digital social research? In lieu of a longer argument, let me offer a few starting points by way of some quotations.

Everything starts, first, from the fact of interdependence as a basic characteristic of human life. How we are interrelated, and what particular material forms of interdependence become important at different times and places historically is highly contingent, but the fact that social order is built from the necessity of human relations remains. This point is elegantly summed up in historian William Sewell's statement that 'the social' is simply 'the various mediations that place people into "social" relations with one another' (2005, p. 329). Digital social research foregrounds those changing 'mediations'.

Those mediations are only possible, second, on the basis of a material infrastructure. The social world is therefore always double in nature, both form of meaning and built environment (Couldry and Hepp 2016, p. 3, drawing on Sewell 2005 , p. 321). It follows that digital social research is always both about complexities of meaning and about complexities of environment, and the endless interrelations between those two sorts of complexity.

Third, developing the same point about doubleness, infrastructures are built both through material connections and through new configurations of actors and actions based in meaning, and in particular in changing regimes of value. In his last book on the profound social changes that flowed from new uses of the written word from the $11^{\text {th }}$ century onwards, social theorist Ivan Illich expressed this in terms of changes in the 'axioms' of human life. 'Axioms' are what is valued: they congeal an 'understanding of the world, society and self (Illich 1994, p. 4, discussed by Couldry and Hepp 2016, p. 8), and make it practical. The world is currently going through a transformation of the axioms around which human interdependence is configured. That, above all, is what makes digital platforms important for social research, because they configure what counts as social in new ways. 
For this reason, finally, relations of power are at the heart of digital social research. Counting this as that is already a relation of power, or at least a claim on power, which may or may not be instantiated in practice (Bowker and Star 1999; Espeland and Sauder 2007). French sociologist Luc Boltanski expresses this same principle beautifully in his book On Critique which attempts to re-ground social critique in a deeply pluralist and materialist framework. (2011, p. 57). 'Reality', he writes 'tends to coincide with what appears to hang together ... [that is] with order'. Order however is not natural, but highly contingent, shaped by the changing institutions that have power over 'the whatness of what is' (2011, p. 57, p. 56, added emphasis). Boltanski's main example is law, but the same argument applies well to media institutions' historic role in naming reality and, perhaps even better, to the role of platforms and their underlying artificial intelligence processes in categorising the flow of social life so that data from it can be processed for value.

The outcome is a different type of social texture, still meaningful of course and without doubt still an environment, but differently negotiable from earlier social textures: a difference captured perhaps by the passive voice in the terms 'platformed sociality' or 'computed sociality' (respectively, Van Dijck 2013, p. 5; Alaimo and Kallinikos 2017, p. 177, added emphases).

Is the territory of social research that results from taking 'the digital' seriously an intimidating, even a disturbing one? Certainly. Is it exciting? You bet it is.

\section{REFERENCES}

Alaimo, C. \& Kallinikos, J. (2017) 'Computing the Everyday: Social Media as Data Platforms.' The Information Society, 33 (4), pp. 175-191, https://doi.org/10.1080/01972243.2017.1318327

Boltanski, L. (2011) On Critique. London: Verso.

Bowker, G. \& Leigh Star, S (1999) Sorting Things Out. Cambridge, MA: MIT Press.

Couldry, N. (2008) 'Actor Network Theory and Media: Do They Connect and On What Terms?' in Hepp, A., Krotz, F., Moores, S. \& Winter, C. (eds) Cultures of Connectivity. Creskill, NJ: The Hampton Press, pp. 93-110.

Couldry, N. (2012) Media Society World. Cambridge: Polity.

Couldry, N. \& Hepp, A. (2016) The Mediated Construction of Reality. Cambridge: Polity.

Couldry, N., Dickens, L., \& Fotopoulou, A. (2016) 'Real Social Analytics: A Contribution to the Phenomenology of the Digital World', British Journal of Sociology, 67(1), pp. 118-137, https://doi.org/10.1111/1468-4446.12183.

Deuze, M. (2012) Media Life. Cambridge: Polity.

Espeland, W. \& Sauder, M. (2007) 'Rankings and Reactivity: How Public Measures Recreate Social Worlds.' American Journal of Sociology, 113(1), pp. 1-40, https://doi.org/10.1086/517897. 
Illich, I. (1996) In the Vineyard of the Text. Chicago: Chicago University Press. Latour, B. (2005) Reassembling the Social. Oxford: Oxford University Press.

Sewell, W. (2005) Logics of History. Chicago: Chicago University Press, https://doi.org/10.7208/chicago/9780226749198.001.0001.

Van Dijck, J. (2013) The Culture of Connectivity. Oxford: Oxford University Press, https://doi.org/10.1093/acprof:oso/9780199970773.001.0001. 